\title{
Technical Note: Effect of Sample Processing Procedures on Measurement of Starch in Corn Silage and Corn Grain ${ }^{1}$
}

\author{
M. B. Hall ${ }^{2}$ and D. R. Mertens \\ US Dairy Forage Research Center, USDA-ARS, Madison, WI 53706
}

\begin{abstract}
Methods for processing feedstuffs before analysis can affect analytical results. Effects of drying temperature (corn silage), preservation method (corn grain), and grinding method (corn silage and grain) on starch analysis values were evaluated. Corn silage samples dried at 55 or $105^{\circ} \mathrm{C}$ and grain samples dried at $55^{\circ} \mathrm{C}$ were ground to pass the $1-\mathrm{mm}$ screen of an abrasion mill or cutting mill and analyzed for free glucose and starch corrected for free glucose. Starch analyses were performed in triplicate to assess the effect of treatment on precision of starch determination. Drying at $105^{\circ} \mathrm{C}$ decreased free glucose and tended to decrease starch detected in silage. Decreased free glucose and starch values in silages dried at $105^{\circ} \mathrm{C}$ may have been caused by the destruction of glucose and production of Maillard products through nonenzymatic browning. Maillard products with reducing activity could potentially interfere with the glucose oxidase-peroxidase glucose detection method used. Compared with the cutting mill, grinding samples through the abrasion mill increased the precision of starch measures in silage, likely due to the effect of the finer particle size produced by the abrasion mill allowing more accurate subsampling of a more homogeneous matrix. Starch values were greater for grain ground with an abrasion mill than with a cutting mill, with the difference greater for dry-rolled than for high-moisture corn. For starch analysis of corn silage and corn grain, drying at lower temperatures $\left(55^{\circ} \mathrm{C}\right)$ in forced-air ovens and grinding through the 1-mm screen of an abrasion mill or its equivalent is recommended.
\end{abstract}

Key words: starch, analysis, corn silage, nonfiber carbohydrate

\footnotetext{
Received March 14, 2008.

Accepted August 14, 2008.

${ }^{1}$ Mention of any trademark or proprietary product in this paper does not constitute a guarantee or warranty of the product by the USDA or the Agricultural Research Service and does not imply its approval to the exclusion of other products that also may be suitable.

${ }^{2}$ Corresponding author: MaryBeth.Hall@ars.usda.gov
}

Methods of feed sample preparation for compositional analysis typically describe allowable drying temperatures and method of grinding, with mesh or screen size specifications provided. These details are given to minimize changes in composition due to insufficient drying or excessive heating, and to give a sample particle size with optimum filtration and extraction characteristics for a particular assay. If several options can be used for sample preparation without compromising analytical results, laboratories can have more flexibility in utilizing equipment or procedures they already employ and of developing sample processing schemes in which a single preparation method accommodates multiple assays. The objective of this study was to evaluate the effects of 2 drying temperatures (silage), method of processing (grain), and mill type used for grinding samples (grain and silage) on measured starch and free glucose (Glc) concentrations in corn silage and corn grain.

Corn silage samples $(\mathrm{n}=9)$ were subsampled and dried in forced-air ovens at 55 or $105^{\circ} \mathrm{C}$. Samples subject to different temperature treatments were dried in different ovens that may have differed in air flow. For each sample and each drying temperature, approximately $400 \mathrm{~g}$ of wet silage was placed in a $20 \mathrm{~cm} \times 20 \mathrm{~cm} \times 5$ $\mathrm{cm}$ (silage depth approximately $6 \mathrm{~cm}$ ) aluminum pan. Samples dried at $55^{\circ} \mathrm{C}$ were dried in a Yamato DKN600 mechanical convection oven with forced-air circulation $(60 \mathrm{~cm} \times 50 \mathrm{~cm} \times 50 \mathrm{~cm}$ internal dimensions; Yamato Scientific America Inc., Santa Clara, CA); samples occupied $29 \%$ of the volume of the oven. Samples dried at $105^{\circ} \mathrm{C}$ were dried in an American Scientific Products (Columbus, OH) DK62 mechanical convection oven with forced-air circulation $(60 \mathrm{~cm} \times 50 \mathrm{~cm} \times 55 \mathrm{~cm}$ internal dimensions); samples occupied $26 \%$ of the volume of the oven. For both drying treatments, samples were placed in the ovens at $1100 \mathrm{~h}$, removed from the ovens at $1700 \mathrm{~h}$, mixed manually to enhance drying, replaced in the ovens, and removed from the ovens at $0900 \mathrm{~h}$ the following morning. Samples were held at ambient temperature and humidity for $1 \mathrm{~d}$ before they were ground. Each entire sample was ground to pass the 8-mm screen of a cutting mill (Wiley mill, Arthur H. Thomas Co., Philadelphia, PA) to increase the accuracy of subsampling. Ground samples were mixed and 
subsampled, and 40- to 50-g subsamples (representing approximately 30 to $40 \%$ of the total dried sample) were ground through the $1-\mathrm{mm}$ screen of a cutting mill or abrasion mill (Udy Corp., Fort Collins, CO) for each drying treatment for each silage sample. Four drying temperature $\times$ grinding method treatments were obtained for each silage sample processed. Sample DM of the processed samples was determined as loss on drying at $105^{\circ} \mathrm{C}$ for $24 \mathrm{~h}$.

Corn grain samples ( 5 dry rolled, DRC; 4 high moisture, HMC; donated by G. E. Erickson, University of Nebraska, Lincoln; 4 hybrids had HMC and DRC for the same growing season) were dried at $55^{\circ} \mathrm{C}$ with the same procedure for drying and grinding as applied to the silage samples, giving 2 grinding treatments per grain sample. Based on the silage results, we chose to evaluate only the effects of grinding method with the grain.

Analyses for free Glc and starch were performed with all treatments for a given silage or grain sample evaluated together in a single run. One or 2 corn silage samples and 3 corn grain samples were analyzed in each run, with all starch analyses for silage completed in 6 runs and grain in 3 runs. For both assays, samples were weighed into $25-\times 150-\mathrm{mm}$ Pyrex screw-cap tubes with polytetrafluoroethylene liners, and $30 \mathrm{~mL} /$ tube of 0.1 $M$ sodium acetate buffer $(\mathrm{pH} 5.00 \pm 0.05)$ was added. Starch and free Glc assay incubations were performed in forced-air ovens.

For free Glc analysis, samples were analyzed in duplicate and Glc and a reagent blank analyzed singly. Air-dry samples of $0.2,0.1$, and $0.1 \mathrm{~g}$ were weighed into each replicate tube for silage, grain, and Glc (G7021, Sigma Aldrich, St. Louis, MO), respectively. No substrate was added for reagent blanks. Samples were incubated in tubes with sodium acetate buffer for $1 \mathrm{~h}$ at $100^{\circ} \mathrm{C}$ with no enzymes added. Samples were vortexed before and thrice during incubation.

Samples were analyzed for starch according to a modified method of Bach Knudsen (1997), with silage or grain samples analyzed in triplicate, and control samples and reagent blanks analyzed singly. Sample weights of air-dry sample per replicate were $0.2 \mathrm{~g}$ for silage, and $0.1 \mathrm{~g}$ for grain, corn starch (S-4126, Sigma Aldrich), and Glc. In the initial $100^{\circ} \mathrm{C}$ incubation, 1,740 liquefon units per tube of heat-stable $\alpha$-amylase were used (Spezyme Fred/Multifect AA, made by Genencor, sold by Bio-Cat Inc., Troy, VA). For the $60^{\circ} \mathrm{C}$ incubation, $100 \mathrm{U}$ of amyloglucosidase were added to each tube (EC 3.2.1.3.; E-AMGDF, Megazyme International Ireland Ltd., Bray, Co. Wicklow, Ireland). A final 10min incubation at $100^{\circ} \mathrm{C}$ was omitted. After incubation, high-quality purified water $(20 \mathrm{~mL}$, produced by reverse osmosis) was added to each tube. Sample solu- tions were clarified by centrifugation in $2-\mathrm{mL}$ microfuge tubes at $12,000 \times g$ for $10 \mathrm{~min}$ at ambient temperature in a microcentrifuge (Sorvall Pico, Thermo Electron Corp, Asheville, NC) and diluted on a weight basis with high-quality purified water. Dilution by weight can be particularly useful when solutions are difficult to pipette accurately.

Solution densities of reverse osmosis water and sample solutions (centrifuged at 2,060 $\times g$ in 50 -mL tubes) were measured at ambient temperature $\left(\sim 22^{\circ} \mathrm{C}\right)$ to 0.01 $\mathrm{g}$ accuracy in $10-\mathrm{mL}$ volumetric flasks. Average densities were $0.998 \mathrm{~g} / \mathrm{mL}$ for sample solutions and $0.995 \mathrm{~g} /$ $\mathrm{mL}$ for water.

In free Glc and starch analyses, the final volume of sample solution in each incubated tube was calculated by weight (to $0.01 \mathrm{~g}$ accuracy) as [(final weight of tube + screw cap + sample + added liquids, g) - (initial weight of tube + screw cap + sample, g)]/(average density of the sample solutions, $\mathrm{g} / \mathrm{mL}$ ). Sample dilution factors were calculated as [(sample solution, g/average sample solution density, $\mathrm{g} / \mathrm{mL}$ ) + (water, $\mathrm{g} /$ water density, $\mathrm{g} / \mathrm{mL})] /($ sample solution, $\mathrm{g} /$ average sample solution density, $\mathrm{g} / \mathrm{mL})$.

Diluted samples were analyzed for Glc using a glucose oxidase-peroxidase reagent in a colorimetric assay (Karkalas, 1985). Absorbance values of reagent blanks were subtracted from sample values. Detected Glc is reported on a starch basis as Glc content $\times 0.9$. Starch content of samples was calculated as the value from the enzymatic assay minus that from the free Glc assay. Recovery (DM basis) of control samples expressed on a starch basis were $90.1 \% \pm 1.4$ for Glc in the free Glc assay and $91.5 \% \pm 0.7$ for Glc and $99.4 \% \pm 0.4$ corn starch in the starch assays (complete recovery values $=$ $90 \%$ for Glc and $100 \%$ for corn starch). The standard deviation of the free Glc-corrected starch value for each sample $\times$ treatment was calculated using 3 replicate analysis values.

Analyses of grain samples to determine why starch content was greater for HMC than for DRC for a given hybrid included NDF (using sulfite and 3 doses of heat-stable $\alpha$-amylase; performed only on cutting mill samples; Mertens, 2002), N (Dumas combustion method, Leco FP-2000, Leco Corporation, St. Joseph, MI) expressed as $\mathrm{CP}(\mathrm{N} \times 6.25)$, and ash (samples ashed at $500^{\circ} \mathrm{C}$ for $4 \mathrm{~h}$ ).

The experimental design was a randomized complete block with a $2 \times 2$ factorial arrangement of treatments (silages: grinding method $\times$ drying temperature; grain: grinding method $\times$ processing method). The model statement used for all tests with silage was

$$
\mathrm{Y}_{\mathrm{jkl}}=\mu+\mathrm{I}_{\mathrm{j}}+\mathrm{G}_{\mathrm{k}}+\mathrm{T}_{\mathrm{l}}+\mathrm{GT}_{\mathrm{kl}}+\varepsilon_{\mathrm{jk} \mathrm{l}},
$$


Table 1. Analytical values for corn silage samples ground through an abrasion mill or a cutting mill and dried at 55 or $105^{\circ} \mathrm{C}^{1}$

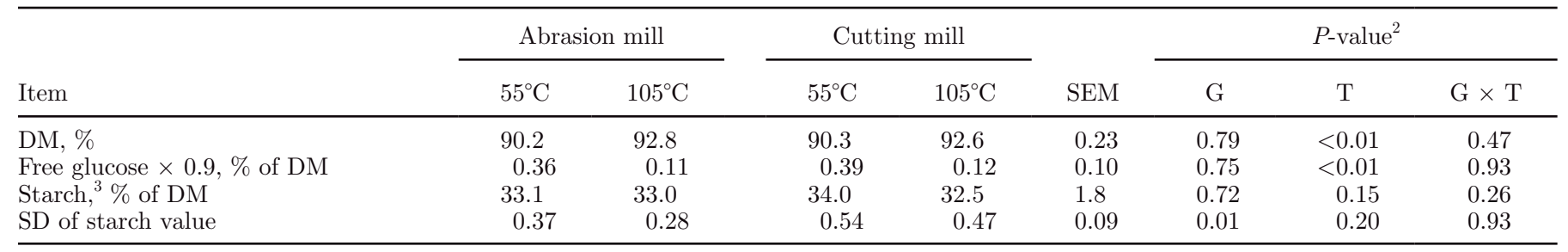

${ }^{1}$ Nine corn silage samples with the 4 treatments applied to each were evaluated. All values expressed as least squares means. Samples were ground through a $1-\mathrm{mm}$ screen in each mill type.

${ }^{2} \mathrm{G}=$ grinding method; $\mathrm{T}=$ drying temperature; $\mathrm{G} \times \mathrm{T}=$ interaction of grinding method and drying temperature.

${ }^{3}$ Starch values are corrected for free glucose.

where $\mathrm{Y}_{\mathrm{jkl}}=$ the dependent variable, $\mu=$ overall mean, $\mathrm{I}_{\mathrm{j}}=$ sample identity $(\mathrm{j}=9$ corn silage samples $), \mathrm{G}_{\mathrm{k}}$ $=$ grinding method $(\mathrm{k}=$ abrasion or cutting mill $)$, $\mathrm{T}_{1}=$ drying temperature $\left(1=55^{\circ}\right.$ or $\left.105^{\circ} \mathrm{C}\right), \mathrm{GT}_{\mathrm{kl}}=$ interaction term for method of grinding and drying temperature, and $\varepsilon_{\mathrm{jkl}}=$ residual error. Sample identity was a random variable and the remainder were fixed variables. For grain samples, the same model and analyses were used, but with $\mathrm{M}_{\mathrm{m}}=$ corn processing ( $\mathrm{m}$ $=\mathrm{DRC}$ or HMC) replacing the $\mathrm{T}_{1}$ term, $\mathrm{I}_{\mathrm{j}}$ representing 9 grain samples, and $\mathrm{GM}_{\mathrm{km}}$ as the interaction term. Average values, not the individual replicate values for DM, starch, and free Glc for each sample, were analyzed. Standard deviation data analyzed to assess the effect of treatment on precision of starch measurements were transformed $\left(\log _{10}\right.$ for corn silage, square root for corn grain) to pass the Shapiro-Wilk test for normality $(P>0.05)$ before analysis. Transformation altered the $P$-values but not the interpretation of the data. Data were analyzed using PROC MIXED of SAS (version 8.0, 1999; SAS Institute Inc., Cary, NC). Significance was declared at $P<0.05$ and tendencies at $0.05>$ $P \leq 0.15$. Values presented are least squares means. Homogeneity of variance tests (Levene's test in PROC GLM) were performed on starch and transformed SD data; all tests gave $P>0.27$, indicating that variances were sufficiently comparable to test for differences with an ANOVA.

Differences in NDF, ash, and CP content between DRC and HMC for grain hybrids (4) that had both sample types were evaluated using a paired $t$-test in SAS. Values for both grinding methods were averaged by DRC and HMC for each hybrid. Values presented are arithmetic means.

Silage samples dried at $105^{\circ} \mathrm{C}$ had greater DM percentage and decreased free Glc content (Table 1). The $105^{\circ} \mathrm{C}$-dried samples and their sample solutions were darker and browner than the $55^{\circ} \mathrm{C}$ samples, suggesting greater progression of Maillard-type nonenzymatic browning in samples dried at the greater temperature, which may be indicative of more extensive destruction of sugars (Hodge and Osman, 1976) and partly explain the lower free Glc values. It is possible that reducing substances produced through nonenzymatic browning (Van Soest, 1994) decreased Glc detection through interference with the reaction catalyzed by glucose oxidase. Such interference could also explain the tendency for decreased starch values in silage dried at $105^{\circ} \mathrm{C}$.

Greater precision of silage starch values was achieved with the abrasion mill (Table 1 ), with the range of starch values $(6 \times \mathrm{SD})$ reduced by $37 \%$, from 3.0 percentage units of DM for the cutting mill to 1.9 for the abrasion mill. Even with screens of the same size, abrasion mills give a finer particle size than do cutting mills, with a 1 -mm abrasion mill grind roughly equivalent to a 0.5 mm cutting mill grind (Mertens, 1991). Silage samples ground with the cutting mill contained recognizable plant parts (fibrous vegetative matter, white specks of grain) that were not visible in the abrasion mill samples. With no difference in starch values, the effect of the abrasion mill could be attributable to more consistent subsampling of a more homogeneous sample.

Grinding method and its interaction with processing affected the measured starch content of grain (Table 2 ). Starch values were $3.4 \%$ of DM greater for DRC ground through an abrasion mill but the effect was not as great for HMC. The lesser effect of grinding for HMC and silage may have partial basis in the more friable nature of not-fully-mature kernels. The finer particle size achieved with an abrasion mill likely increased the access of enzymes to starch and appears to be essential for starch analysis of mature corn preserved in dry form. The smaller SEM and greater content of starch in grain compared with silage could explain why an effect of grinding was detected for HMC but not for silage: the difference was small and if it exists with silage, greater variability in values and a lesser starch content would require more samples to detect it. Unlike those for silage, precision of starch values for grain was unaffected by grinding method, possibly because of the 
Table 2. Analytical values for corn grain samples ${ }^{1}$ ground through an abrasion mill or a cutting mill and dried at 55 or $105^{\circ} \mathrm{C}^{2}$

\begin{tabular}{|c|c|c|c|c|c|c|c|c|}
\hline Item & \multicolumn{2}{|c|}{ Abrasion mill } & \multicolumn{2}{|c|}{ Cutting mill } & SEM & \multicolumn{3}{|c|}{$P$-value ${ }^{3}$} \\
\hline $\mathrm{DM}, \%$ & 94.6 & 95.2 & 93.5 & 94.1 & 0.13 & $<0.01$ & 0.03 & 0.97 \\
\hline Starch, ${ }^{4} \%$ of DM & 73.1 & 74.6 & 69.7 & 74.1 & 0.7 & $<0.01$ & $<0.01$ & $<0.01$ \\
\hline SD of starch value & 0.44 & 0.69 & 0.69 & 0.88 & 0.25 & 0.40 & 0.82 & 0.91 \\
\hline
\end{tabular}

${ }^{1} \mathrm{DRC}=$ dry rolled corn; HMC = high moisture corn.

${ }^{2}$ Nine corn grain samples (5 DRC, $4 \mathrm{HMC}$ ) with the 2 grinding treatments applied to each were evaluated. All values are expressed as least squares means. Samples were ground through a 1-mm screen in each mill type.

${ }^{3} \mathrm{G}=$ grinding method, $\mathrm{M}=$ grain type, $\mathrm{G} \times \mathrm{M}=$ interaction of grinding method and grain type.

${ }^{4}$ Starch values are corrected for free glucose.

greater uniformity of this matrix. The effect of grinding $\times$ processing on free Glc in grain was significant, but, at a difference of $0.05 \%$ of DM for DRC, not of practical importance for feed analysis.

Starch content was greater in HMC than DRC (Table $2)$. Greater NDF content in DRC (8.3\% of DM) than in $\operatorname{HMC}(7.5 \%$ of $\mathrm{DM} ; P=0.04)$ may partly explain the difference as an issue of dilution. No differences were detected between DRC and HMC in CP (8.6 and 8.9\% of DM, respectively; $P=0.20)$ or ash (1.4 and $1.4 \%$ of $\mathrm{DM}$, respectively; $P=0.52$ ). Differences between HMC and DRC that influence destruction of sample structure and availability of starch for hydrolysis may also play a part.

In conclusion, analyzed starch values differed by grinding method in corn grain, and drying temperature tended to affect corn silage values. Drying protocols other than those tested may differ in their effects. Precision of starch values in silage increased with use of the abrasion mill. We recommend that samples for starch analysis not be dried at $105^{\circ} \mathrm{C}$, but at a lower temperature such as $55^{\circ} \mathrm{C}$ in a forced-air oven (to constant weight with periodic mixing to enhance speed of drying); samples should be ground through the 1-mm screen of an abrasion mill or its equivalent (e.g., 0.5-mm cutting mill). This agrees with published recommen- dations (e.g., McCleary et al., 1997) to grind samples to pass a $0.5-\mathrm{mm}$ screen for starch analysis (mill type not specified). Selection of sample processing methods must include consideration of how preparation affects the results of all analyses to be run. Several different preparation methods may be needed if multiple assays with different requirements are performed.

\section{REFERENCES}

Bach Knudsen, K. E. 1997. Carbohydrate and lignin contents of plant materials used in animal feeding. Anim. Feed Sci. Technol. 67:319-338.

Hodge, J. E., and E. M. Osman. 1976. Carbohydrates. Page 83 in Principles of Food Science Part I: Food Chemistry. O. R. Fennema, ed. Marcel Dekker Inc., New York, NY.

Karkalas, J. J. 1985. An improved enzymatic method for the determination of native and modified starch. J. Sci. Food Agric. 36:1019-1027.

McCleary, B. V., T. S. Gibson, and D. C. Mugford. 1997. Measurement of total starch in cereal products by amyloglucosidase- $\alpha$-amylase method: Collaborative study. J. AOAC Int. 80:571-579.

Mertens, D. R. 1991. Critical conditions in determining detergent fibers. Pages 5-11 in National Forage Testing Assoc. Forage Analysis Workshop Proc., Milwaukee, WI. National Forage Testing Assoc., Omaha, NB.

Mertens, D. R. 2002. Gravimetric determination of amylase-treated neutral detergent fiber in feeds with refluxing in beakers or crucibles: Collaborative study. J. Assoc. Off. Anal. Chem. 85:1217-1240.

Van Soest, P. J. 1994. Nutritional Ecology of the Ruminant. Cornell University Press, Ithaca, NY. 